Pure Appl. Chem., Vol. 85, No. 6, pp. 1241-1255, 2013.

http://dx.doi.org/10.1351/PAC-REP-12-08-09

(C) 2013 IUPAC, Publication date (Web): 19 May 2013

\title{
Bibliometric analysis of research on secondary organic aerosols: A Science Citation Index Expanded-based analysis (IUPAC Technical Report)*
}

\author{
Jinfeng $\mathrm{Li}^{1}$, Yuanhang Zhang ${ }^{1}$, Marjan Veber ${ }^{2}$, Paul H. Wine ${ }^{3}$, and \\ Leo Klasinc ${ }^{4, \ddagger}$ \\ ${ }^{1}$ College of Environmental Sciences and Engineering, Peking University, Beijing, \\ China; ${ }^{2}$ Faculty for Chemistry and Chemical Technology, University of Ljubljana, \\ Ljubljana, Slovenia; ${ }^{3}$ School of Chemistry and Biochemistry and School of Earth \\ and Atmospheric Sciences, Georgia Institute of Technology, Atlanta, GA, USA; \\ ${ }^{4}$ Ruđer Bošković Institute, Zagreb, Croatia
}

\begin{abstract}
This study was conceived to evaluate the global scientific output of secondary organic aerosol (SOA) research over the past 20 years and to assess the characteristics of the research patterns, tendencies, and methods in the papers. Data were based on the online version of Science Citation Index Expanded from 1992 to 2011. Publications referring to SOAs were assessed by distribution of the number of publications and times cited, source categories, source journals, author keywords, KeyWords Plus, and the most cited publications in these years. By synthetic analysis of author keywords, KeyWords Plus, titles, and abstracts, it was concluded that modeling is currently and will at least over the next decade continue to be the predominant research method to validate state-of-the-art knowledge of SOAs, and that the foci of SOA research will be the key precursors terpenes and isoprene, the mechanisms of oxidation and gas-phase reactions, and emission inventories.
\end{abstract}

Keywords: bibliometrics; carbon compounds; IUPAC Chemistry and the Environment Division; photodegradation; oxidation; research trends; secondary organic aerosols; word cluster analysis.

\section{INTRODUCTION}

Secondary organic aerosols (SOAs) refer to those organic components of particulate matter that transfer to the aerosol phase from the gas phase as products of the gas-phase oxidation of parent organic species [1]. Recently, aqueous-phase oxidation is also considered as an important source of SOAs [2]. SOAs contribute to many important atmospheric processes, including visibility reduction [3], cloud formation by serving as cloud condensation nuclei [4], and direct and indirect radiative forcing [5], as well as a variety of adverse effects to human health [6] and forests [7].

Organic aerosols (OAs) may be either anthropogenic or natural in origin [8]. The former generally come from the exhaust of combustion sources (power stations; air, water, and land traffic; heating and land reclamation by burning) while the latter can result from physical (weather induced, evaporation/condensation, catastrophic events like wildfire or oil spill), chemical (photo-, thermal-, oxidative,

*Sponsoring body: IUPAC Chemistry and the Environment Division: see more details on p. 1253.

¥Corresponding author 
or reductive degradation; soil/air- and water/air-exchange) or biological (biogenic volatile organic compounds, BVOCs, mostly from plants, spores and pollen, and microbes and viruses) supply of organics to the atmosphere. In a way, all could be considered as primary OAs although generally only the anthropogenic ones are counted as such. They all are sources for SOA formation, which mainly results through the (supposedly) well-known chemistry of tropospheric ozone, but the real SOA production exceeds all model predictions. Poor understanding of source contributions makes the present and future study of SOAs important and necessary. Over the past decade, researchers have devoted efforts to the identification, quantification, and source apportionment of SOAs, and this work has been the subject of several review articles $[1,8-10]$.

Despite the high growth-rate of publications, there have been few attempts to gather systematic data on the global scientific production of research on SOAs, except for two bibliometric studies on aerosol by Xie et al. [11] and Zhang et al. [12]. A common research tool for this analysis is the bibliometric method. The Science Citation Index Expanded (SCI-EXPANDED) from the Institute of Scientific Information (ISI) Web of Science databases is the most important and frequently used source for a broad review of scientific accomplishment in all fields [11,13-16].

In this study, a traditional bibliometric method (analysis of the number of publications and times cited, subject categories, and the most-cited papers) is used to describe the latest advances in SOA research. Moreover, an innovative method-word cluster analysis of selected topics in the combination of paper titles, author keywords, KeyWords Plus, and abstracts [13-15] —is applied to map the global research trends during the period 1992-2011. Findings from these investigations can help researchers to realize the breadth of SOA research and to establish future research directions.

\section{METHODOLOGY}

The data are based on the online version of the database SCI-EXPANDED. According to Journal Citation Reports (JCR), this database indexed 8073 major journals with citation references across scientific disciplines in 2010. However, since a limitation is that most abstracts before 1991 are not included in SCI-EXPANDED [13], we used "secondary organic aerosol" and "secondary organic carbon" as the keywords to search titles, abstracts, and keywords from 1992 to 2011 only. All publications referring to SOAs during the past 20 years were assessed according to the following: characteristics of publication outputs, distribution of outputs in journals, times cited per publication and analysis of paper titles, author keywords, Keyword Plus, and abstracts. The words in titles and abstracts were separated, and then conjunctions and prepositions were discarded, as they were meaningless for further analysis. Keywords were defined as comma-separated items of one or more words. All keywords (1992-2011), both those reported by authors and those attributed by ISI as well as the words in titles and abstracts, were identified and separated into four 5-year periods, and then their ranks and frequencies were calculated in order to thoroughly and precisely analyze the variations of trends. Different words with an identical meaning and misspelled keywords were grouped and considered as a single keyword. For instance, the word "secondary organic aerosol*" represented "secondary organic aerosol", "secondary organic aerosols", "secondary organic aerosol (SOA)", "secondary organic aerosols (SOA)", "secondary organic aerosols (SOAs)", "secondary-organic aerosol", and "SOA". A word cluster analysis combination of the words in titles, author keywords, KeyWords Plus, and words in abstracts was used in the analysis $[13,14]$.

\section{RESULTS AND DISCUSSION}

\section{Characteristics of publication outputs}

SOA research developed rapidly over the last few decades (Fig. 1), especially after 1998, from one publication in 1976 to 322 publications in 2011 with SOA and secondary organic carbon as the search key- 


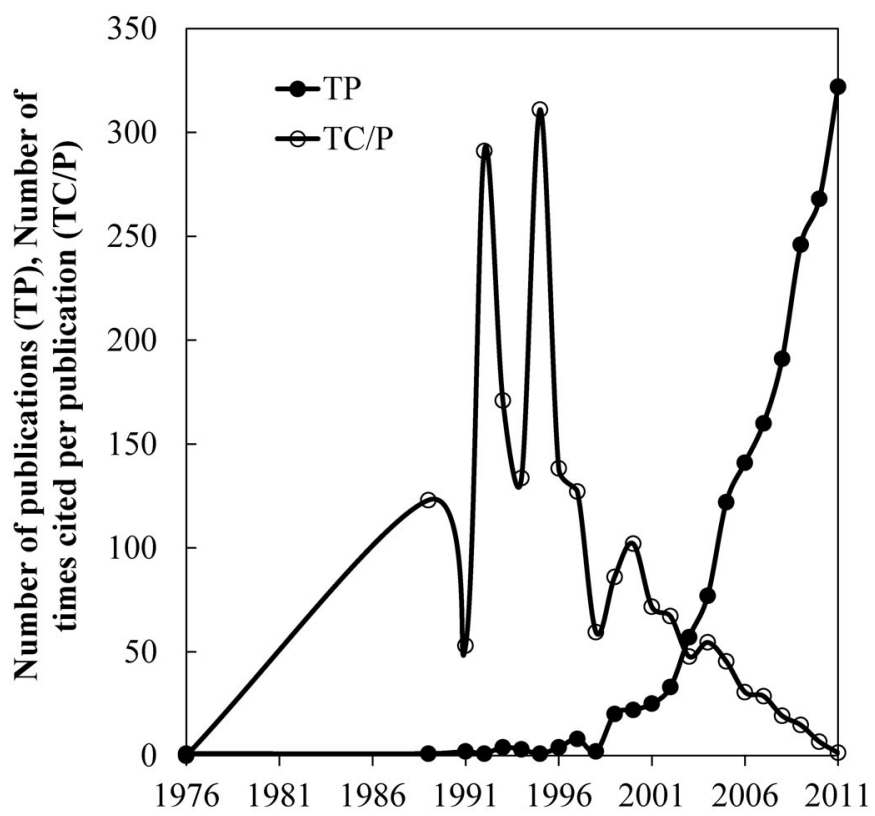

Fig. 1 SCI-EXPANDED journal publications with SOA in topics and the number of times cited per publication during 1976-2011.

words in topics. The number of times cited per publication showed two peaks in 1992 and 1995 with 291 for Pandis et al. [17] and 311 for Turpin and Huntzicker [18]. Pandis et al. [17] developed a Lagrangian trajectory model to simulate the formation, transport, and deposition of SOAs. They pointed out the major uncertainties in predicting SOA concentrations were the reactive organic gas emissions, the aerosol yields, and the partitioning of the condensable gases between the two phases. Turpin and Huntzicker [18] developed a primary aerosol model with the elemental carbon (EC) tracer method to quantify the primary and SOA concentrations during the 1987 Southern California Air Quality Study.

Based on the classification of subject categories in JCR 2010, the publication output data of SOA research was distributed into 35 SCI subject categories during 1976-2011. Subject categories containing more than 200 publications were meteorology and atmospheric sciences (1004), environmental sciences and ecology (781), engineering (359), and chemistry (235).

Papers were published in a wide range of 148 different journals. In this particular research field, Atmospheric Chemistry and Physics published the most articles (332, 19.4\%). Close on its heels was Atmospheric Environment with 324 (18.9\%). Environmental Science and Technology ranked third with $232(13.6 \%)$, the Journal of Geophysical Research-Atmospheres ranked fourth with 167 (9.8\%), and Aerosol Science and Technology ranked fifth with 53 (3.1\%). From 1989 to 2007, Atmospheric Environment always held primacy; however, the number of publications in Atmospheric Chemistry and Physics (which published its first issues in 2001) grew quickly and has exceeded that in Atmospheric Environment since 2008 (Fig. 2).

During 1976-2011, J. H. Seinfeld from the California Institute of Technology authored the most publications $(112,6.9 \%)$ related to SOA in SCI-EXPANDED. S. N. Pandis from the California Institute of Technology and Carnegie Mellon University ranked second with $60(3.5 \%)$, followed by U. Baltensperger (56; $3.3 \%$ ) from Paul Scherrer Institut; J. L. Jimenez (54, $3.1 \%$ ) from the University of Colorado, Boulder; and N. M. Donahue $(53,2.9 \%)$ from Carnegie Mellon University. A bias in analysis of authorship might occur when different authors had the same name or one author used different names (e.g., maiden names) in their articles [19]. The contributions of different institutes were esti- 




Fig. 2 Comparisons of growth trends of the top five productive journals. ACP, Atmospheric Chemistry and Physics; AE, Atmospheric Environment; EST, Environmental Science and Technology; JGR, Journal of Geophysical Research-Atmospheres; AST, Aerosol Science and Technology.

mated by the affiliation of corresponding author. There are 1641 publications with information of corresponding author. In total, there are 428 institutes, 247 (57.6\%) of which published only one article. Leading were Carnegie Mellon University $(65,4.0 \%)$, the California Institute of Technology (64, $3.9 \%$ ), the Chinese Academy of Sciences $(41,2.5 \%)$, the University of California, Irvine (41, $2.5 \%$ ), and the University of California, Riverside (40, $2.4 \%$ ). However, a bias appeared because the Chinese Academy of Sciences has over 100 branches in different cities. At present, the publications of the Chinese Academy of Sciences were pooled as one heading, and publications divided into branches would result in different rankings [14].

The Pearl River Delta (PRD) and Megacity Initiative: Local and Global Research Observations (MILAGRO) projects, two atmospheric research field campaigns in 2006 and 2009, respectively, were dedicated to evaluating the roles of ozone, precursors, reaction products, meteorology, geography, etc. in development of air pollution and its hazardous effects in megacities and their surroundings. Both campaigns confirmed the importance of SOA formation as an important component in megacity air pollution. Through the end of 2011, a total of 12 and 31 publications based on the PRD and MILAGRO campaigns, respectively, are indexed in SCI-EXPANDED.

\section{Distribution of author keywords analysis}

Author keywords analysis offers information about research trends as viewed by researchers. Bibliometric methods concerning author keywords have only been used in recent years [20], and their use in analyzing research trends is rare [11,13,14,16]. In 1707 publications from 1992 to 2011, 599 (35.1\%) had author keywords.

Author keywords that appeared in publications referring to SOAs from 1992 to 2011 were counted and ranked in four 5-year periods (Table 1), from which the most frequently used keywords were identified; they include "organic carbon", " $\mathrm{PM}_{2.5}$ ", "ozone", "elemental carbon", and "isoprene". 
SOA is the major component of $\mathrm{PM}_{2.5}$. Ozone oxidizes the precursors of SOA, such as isoprene. Other precursors can be identified from Table 1, such as "alpha-pinene", "terpene*", "monoterpene*", and "toluene". Words with "**" included their single and plural forms. Besides the words with carbon and aerosol, most words appeared in the second or the third 5-year period. The analysis of author keywords demonstrated that the most popular research methods were "source apportionment", "smog chamber", "air quality modeling", "OC/EC ratio", and "aerosol mass spectrometer".

Table 1 Top 26 most frequent author keywords used during 1992-2011 in four 5-year periods.

\begin{tabular}{|c|c|c|c|c|c|c|}
\hline & $\mathrm{TP}$ & $\begin{array}{l}92-11 \\
\mathrm{R}(\%)\end{array}$ & $\begin{array}{l}92-96 \\
\mathrm{R}(\%)\end{array}$ & $\begin{array}{l}97-01 \\
\mathrm{R}(\%)\end{array}$ & $\begin{array}{l}02-06 \\
\mathrm{R}(\%)\end{array}$ & $\begin{array}{l}07-11 \\
\mathrm{R}(\%)\end{array}$ \\
\hline econdary organic aerosol* & 267 & $1(45)$ & (50) & $1(56)$ & 1(49) & $1(42)$ \\
\hline ganic c & 0 & & (17) & $23(3.7)$ & $3(11)$ & $2(11)$ \\
\hline $\mathrm{PM}_{2.5}$ & 58 & $3(10)$ & N/A & $10(7.4)$ & $2(12)$ & $3(9.0)$ \\
\hline ozone & 51 & $4(8.5)$ & N/A & 2(19) & $5(10)$ & $5(7.3)$ \\
\hline elemental carbon & 44 & $5(7.3)$ & $4(17)$ & N/A & $6(7.7)$ & $4(7.5)$ \\
\hline late ma & 43 & $6(7.2)$ & N/A & $10(7.4)$ & $3(11)$ & $7(5.8)$ \\
\hline aeros & 34 & $7(5.7)$ & $4(17)$ & $10(7.4)$ & $8(6.5)$ & $9(5.3)$ \\
\hline aerosol* & 32 & $8(5.3)$ & $4(17)$ & 4(11) & $6(7.7)$ & $10(3.8)$ \\
\hline isoprene & 31 & $9(5.2)$ & N/A & N/A & $34(1.8)$ & $6(7.0)$ \\
\hline source & 29 & 10( & & $\mathrm{N}$ & & $7(5.8)$ \\
\hline alpha- & 25 & 11( & $\mathrm{N} / \mathrm{t}$ & $4(11)$ & 10 & $12(3.5)$ \\
\hline terpene & 23 & 12( & N/A & $10(7.4)$ & $107(0.6)$ & $10(3.8)$ \\
\hline volatile & 20 & 13( & N/A & $4(11)$ & $34(1.8)$ & $12(3.5)$ \\
\hline monoterpene* & 19 & $14(3.2)$ & N/A & $4(11)$ & $13(3.6)$ & $22(2.0)$ \\
\hline $\mathrm{PM}_{10}$ & 19 & $14(3.2)$ & N/A & $10(7.4)$ & $16(3.0)$ & $18(3.0)$ \\
\hline & 18 & & N/A & N/A & & $15(3.3)$ \\
\hline oligomer* & 16 & 17( & $\mathrm{N} /$ & $\mathrm{N} /$ & 13 & $22(2.0)$ \\
\hline ozonoly & 16 & $17(2.7)$ & N/A & N/A & $53(1.2)$ & $12(3.5)$ \\
\hline secondary $\mathrm{o}$ & 16 & $17(2.7)$ & N/A & $10(7.4)$ & $16(3.0)$ & $21(2.3)$ \\
\hline carbonaceous aerosol* $*$ & 15 & $20(2.5)$ & $4(17)$ & N/A & $24(2.4)$ & $15(3.3)$ \\
\hline atmospheric aerosol* & 14 & $21(2.3)$ & N/A & N/A & $24(2.4)$ & $19(2.5)$ \\
\hline atmospheric chemistry & 14 & $21(2.3)$ & N/A & N/A & $9(5.4)$ & $40(1.3)$ \\
\hline toluene & 14 & $21(2$ & N/A & $23(3.7)$ & & $22(2.0)$ \\
\hline lelina & 13 & $24(2.2)$ & N/A & N/A & $12(4.2)$ & $33(1.5)$ \\
\hline & 13 & $24(2.2)$ & N/A & $4(11)$ & $24(2.4)$ & $33(1.5)$ \\
\hline reaction mechanism & 13 & $24(2.2)$ & N/A & N/A & N/A & $15(3.3)$ \\
\hline
\end{tabular}

TP, total number of publications; R (\%), rank and percentage of author keywords in total publications. Words with “*” included their single and plural forms.

\section{Distribution of Keywords Plus analysis}

In the ISI database, KeyWords Plus supplies additional search terms extracted from the titles of articles cited by authors in their bibliographies and footnotes, thereby substantially augmenting title-word and author-keyword indexing [21]. In 1707 publications from 1992 to 2011, 1643 (96\%) had Keywords Plus.

Other than "secondary organic aerosol*", the search keyword in this study, the top six most frequent Keywords Plus were "alpha-pinene", "particulate matter", "particle*”, "photooxidation”, "oxidation", and "emission*". Words with "*" included their single and plural forms. Alpha-pinene from biogenic emissions seems one of the most important precursors of SOA. Oxidation is the main chemical mechanism that forms SOA. Emission inventories are one of the hot topics because they are necessary 
for accurate modeling. Other research topics can be identified from Table 2, such as "chemical-composition", "product*", and "United-States". Words with "*" included their single and plural forms. The rank and percentage of publications with "chemical-composition", "United-States", and "mass-spectrometry" went up from \#106 (1.3\%) during 1992-1996 to \#4 (13\%), \#10 (9.3\%) and \#11 (9.1\%) during 1997-2001, 2002-2006, and 2007-2011, respectively. Much research focused on elucidation of the chemical composition of SOA. Mass spectrometry is a widely used analytic technique for exploring SOA chemical composition.

Table 2 Top 25 most frequently used Keywords Plus during 1992-2011 in four 5-year periods.

\begin{tabular}{|c|c|c|c|c|c|c|}
\hline 1992-2011 & $\mathrm{TP}$ & $\begin{array}{l}92-11 \\
\mathrm{R}(\%)\end{array}$ & $\begin{array}{l}92-96 \\
\mathrm{R}(\%)\end{array}$ & $\begin{array}{l}97-01 \\
\mathrm{R}(\%)\end{array}$ & $\begin{array}{l}02-06 \\
\mathrm{R}(\%)\end{array}$ & $\begin{array}{l}07-11 \\
\mathrm{R}(\%)\end{array}$ \\
\hline secondary organic aerosol* & 561 & $1(34)$ & $14(9.1)$ & $2(25)$ & $1(30)$ & $1(37)$ \\
\hline alpha-pinene & 253 & $2(15)$ & $14(9.1)$ & $4(20)$ & $2(17)$ & $3(15)$ \\
\hline particulate matter & 242 & $3(15)$ & N/A & $32(6.7)$ & $4(14)$ & $2(16)$ \\
\hline particle* & 201 & $4(12)$ & $14(9.1)$ & $17(9.3)$ & $3(16)$ & $6(11)$ \\
\hline photooxidation & 184 & $5(11)$ & $2(27)$ & $12(11)$ & $11(10)$ & $5(12)$ \\
\hline oxidation & 181 & $6(11)$ & N/A & $7(12)$ & $7(12)$ & $7(11)$ \\
\hline emission* & 166 & $7(10)$ & $4(18)$ & $22(8.0)$ & & $9(10)$ \\
\hline ozone & 164 & $8(10)$ & $4(18)$ & $7(12)$ & $6(14)$ & $16(7.3)$ \\
\hline chemical-composition & 163 & $9(10)$ & N/A & $106(1.3)$ & $35(4.3)$ & $4(13)$ \\
\hline biogenic hydrocarbons & 155 & $10(9.4)$ & N/A & $17(9.3)$ & $4(14)$ & $14(7.9)$ \\
\hline source apportionment & 154 & $11(9.4)$ & N/A & $52(4.0)$ & $19(7.5)$ & $8(10)$ \\
\hline United-States & 147 & $12(8.9)$ & $14(9.1)$ & $106(1.3)$ & $13(9.4)$ & $10(9.3)$ \\
\hline atmospheric aerosol $*$ & 139 & $13(8.5)$ & $14(9.1)$ & $37(5.3)$ & $15(8.7)$ & $12(8.6)$ \\
\hline product* & 135 & $14(8.2)$ & N/A & $17(9.3)$ & $16(8.5)$ & $13(8.1)$ \\
\hline chemistry & 125 & $15(7.6)$ & $14(9.1)$ & $12(11)$ & $23(7.0)$ & $15(7.6)$ \\
\hline model* & 124 & $16(7.5)$ & $14(9.1)$ & $7(12)$ & $18(7.7)$ & $17(7.2)$ \\
\hline mass-spectrometry & 121 & $17(7.4)$ & $14(9.1)$ & $106(1.3)$ & $46(3.6)$ & $11(9.1)$ \\
\hline absorption-model & 119 & $18(7.2)$ & $14(9.1)$ & $1(29)$ & $8(11.0)$ & $34(4.5)$ \\
\hline elemental carbon & 119 & $18(7.2)$ & $2(27)$ & $22(8.0)$ & $22(7.2)$ & $18(7.0)$ \\
\hline beta-pinene & 115 & $20(7.0)$ & $4(18)$ & $3(24)$ & 11(10) & $32(4.7)$ \\
\hline gas-phase reaction* & 110 & $21(6.7)$ & N/A & $5(15)$ & $17(8.2)$ & $21(5.6)$ \\
\hline atmospheric particles & 103 & $22(6.3)$ & N/A & $7(12)$ & $19(7.5)$ & $22(5.5)$ \\
\hline identification & 97 & $23(5.9)$ & N/A & $22(8)$ & $9(10)$ & $37(4.3)$ \\
\hline isoprene & 97 & $23(5.9)$ & $14(9.1)$ & $74(2.7)$ & $40(3.9)$ & $19(6.8)$ \\
\hline aromatic-hydrocarbons & 96 & $25(5.8)$ & N/A & $12(11)$ & $25(6.3)$ & $23(5.4)$ \\
\hline
\end{tabular}

TP, total number of publications; $\mathrm{R}(\%)$, rank and percentage of keywords plus in total publications. Words with "** included their single and plural forms.

\section{Hot issues}

In order to overcome the weaknesses of each of the four separate types of keyword analysis, paper titles, author keywords, KeyWords Plus, and abstracts were combined. Then, synonymic single words and congeneric phrases were summed and grouped into categories, so as to analyze the historical development of the science more completely and precisely and, more importantly, to discover the chronology of new directions in the science. This is a new method named "word cluster analysis" that has been applied to analysis of research trends in atmospheric simulation [14], risk assessment [15], and climate change [13]. The words listed in Figs. 3-6 all include their plural forms, abbreviations, and other transformations, as well as words with similar meanings. 


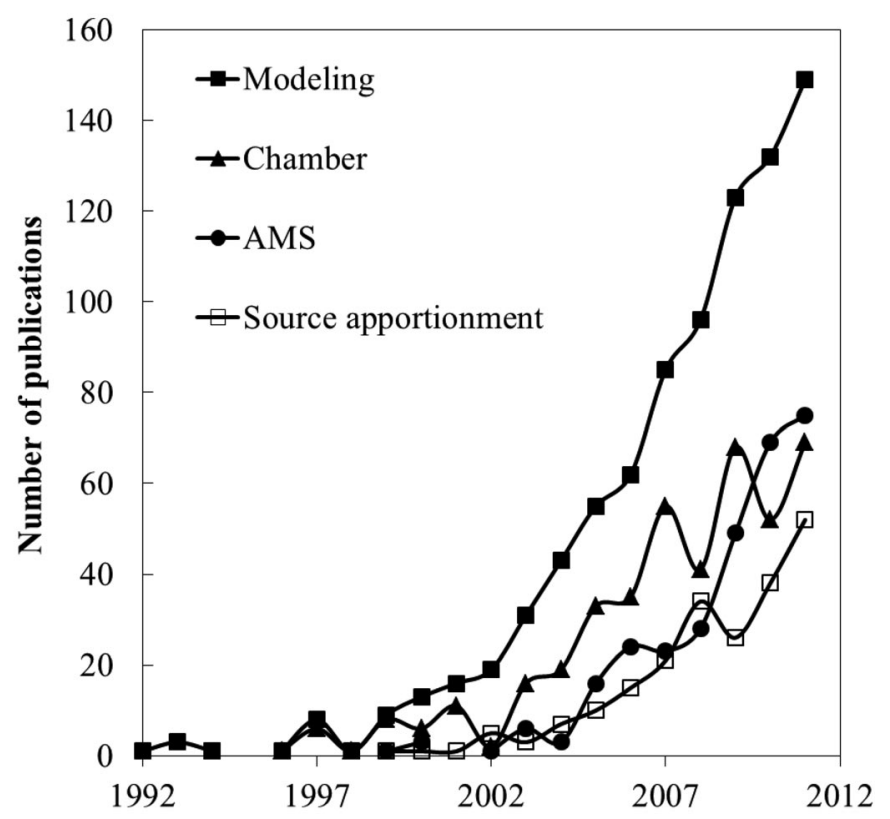

Fig. 3 Comparison of the trends of research methods during 1992-2011. AMS, Aerodyne Aerosol Mass Spectrometer.

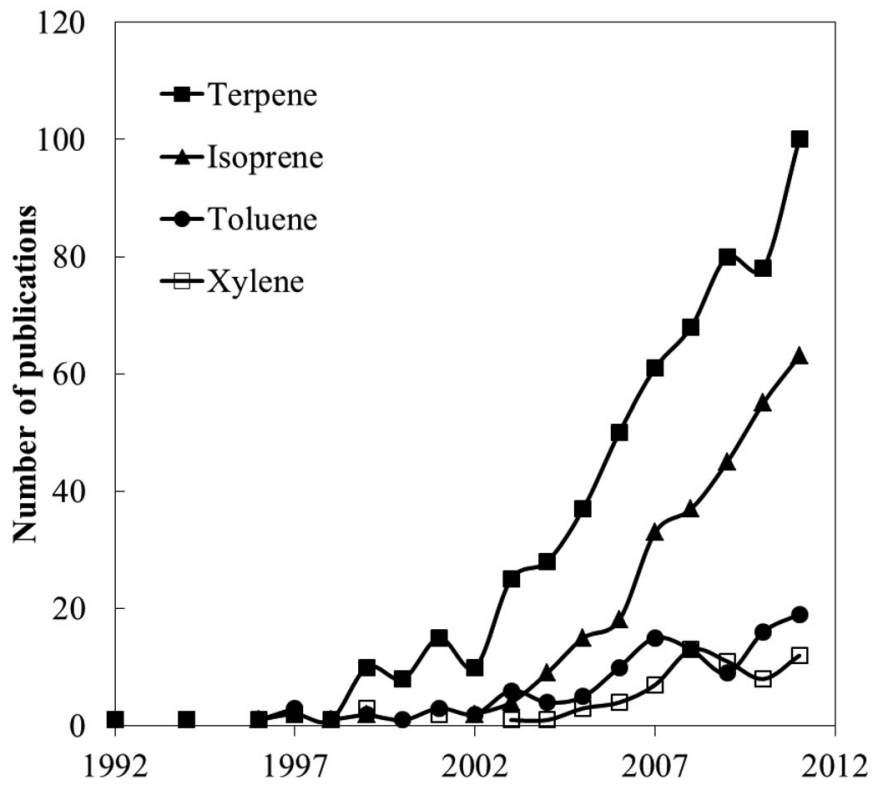

Fig. 4 Comparison of the trends of precursors and sources during 1992-2011. 


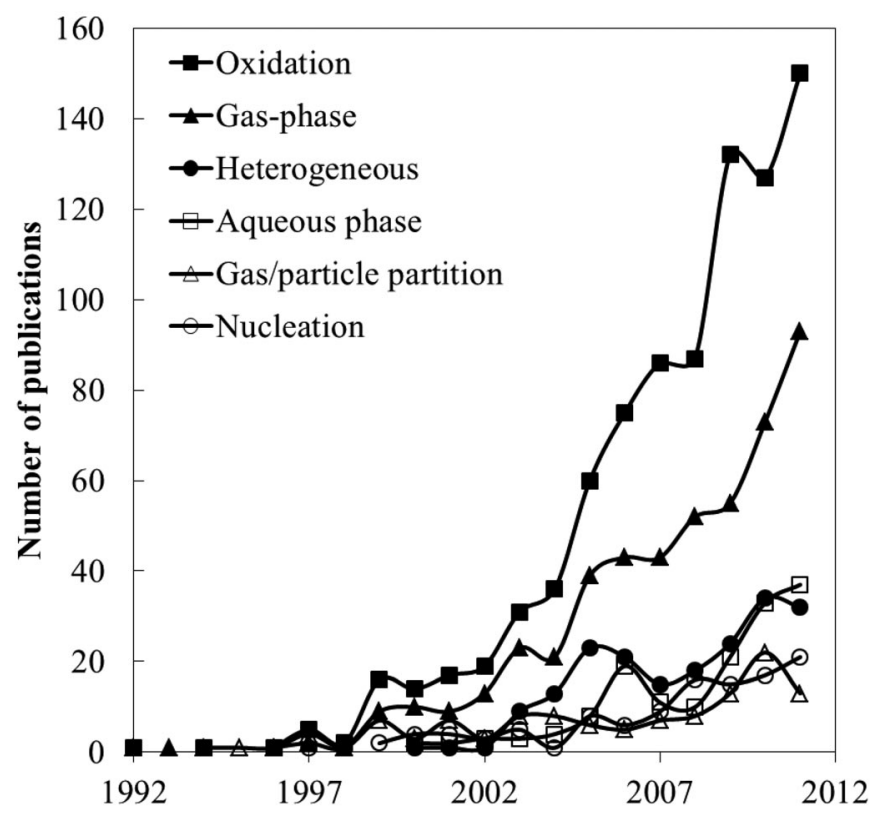

Fig. 5 Comparison of the trends of formation mechanisms during 1992-2011.

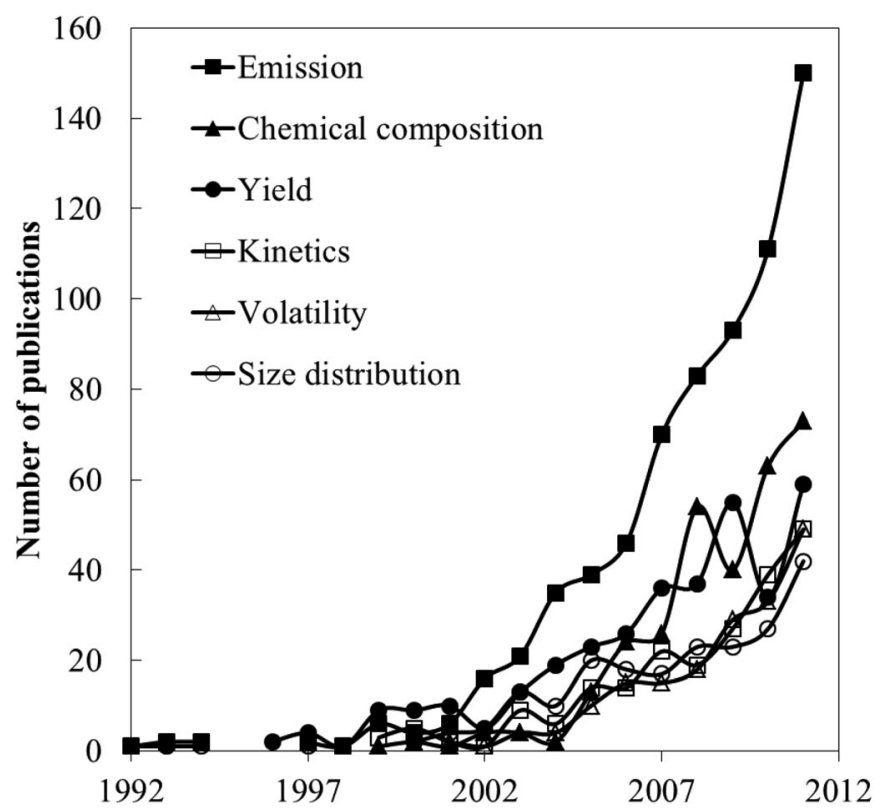

Fig. 6 Comparison of the trends of research topics during 1992-2011.

The analysis described above suggests that modeling, chamber studies, aerosol mass spectrometry (AMS), and source apportionment are the most popular methods in SOA research (Fig. 3). Modeling is the most predominant. Modeling is a powerful tool to assess our knowledge of atmospheric processes related to SOAs, including emissions [1,22], chemical formation [23,24], transport [17], deposition [25], and gas/particle partitioning [26,27]. Various models have been developed to simulate SOAs, such 
as the Lagrangian trajectory model [17], the gas/particle partitioning absorption model [26], the secondary organic aerosol model (SORGAM) [27], Particulate Matter Comprehensive Air-quality Model with extensions (PMCAMx) [28], Community Multiscale Air Quality (CMAQ) [29], Weather Research and Forecasting-Chemistry (WRF-Chem) [30], and the 2D volatility basis set (2D-VBS) modeling framework [24]. Chamber experiments were developed to quantify the aerosol formation potential (aerosol yield) of SOA precursors, such as aromatics [31-33], alkanes [34], monoterpenes [35], isoprene, and $\alpha$-pinene [36]. Chamber experiments are also useful to elucidate fundamental aspects such as chemical mechanisms and gas/particle partitioning of a given mixture of products which, hopefully, can be employed to gain useful knowledge about the occurrence of such processes in the atmosphere [9]. AMS allows for online measurements of OAs with high time-resolution [37]. While AMS provides some information about the chemical composition of OAs, the identification of specific chemical markers is required for more comprehensive source apportionment. Methods for source apportionment include the EC tracer method [18,28] and its variant the CO tracer method [38], positive matrix factorization (PMF) [40], and chemical mass balance (CMB) [41,42]. AMS is often combined with PMF $[43,44]$.

Biogenic hydrocarbons, anthropogenic hydrocarbons, and organic compounds generated from biomass burning are three main precursors of SOAs, among which terpenes, isoprene, toluene, and xylenes have attracted the most attention (Fig. 4). Terpenes and isoprene (2-methyl-1,3-butadiene) are of biogenic origin, while toluene and xylenes are anthropogenic. The major anthropogenic sources are small aromatic compounds such as benzene, toluene, xylenes, and trimethylbenzenes [31]. Many biogenic hydrocarbons show much higher reactivity towards the important atmospheric oxidants $\mathrm{OH}, \mathrm{NO}_{3}$, and ozone than the anthropogenically emitted volatile organic compounds (VOCs), which adds further to the significance of VOCs emitted from biogenic sources (BVOCs) as a major potential contributor to global organic particulate matter formation [45]. In China, anthropogenic sources were found to contribute $35 \%$ of total SOAs in 2006, with seasonal contributions being 41, 26, 39, and $59 \%$ in spring, summer, autumn, and winter, respectively [30]. Isoprene accounts for about half of all natural VOC emissions and is, on a mass basis, the dominant emitted BVOC component [1]. Biogenic hydrocarbons play a significant role in the formation of SOAs, and that even applies in urban areas with high anthropogenic emissions [46]. There is still a paucity of data on, and understanding of, the composition and the properties of aerosols formed from the gas-phase photooxidation of biogenic hydrocarbons [1]. As a result, research on the contribution of terpenes and isoprene to SOAs has grown faster than research on other SOA precursors.

The formation mechanisms with most publications are shown in Fig. 5. The first four mechanisms-oxidation, gas-phase, heterogeneous, and aqueous-phase reactions-are chemical processes. Actually, the atmosphere is an oxidizing environment so gas-phase, aqueous-phase, and heterogeneous reactions all tend to be primarily oxidation reactions. The next two mechanisms, gas/particle partition and nucleation, are physical processes. Typical oxidation processes include $\mathrm{OH}$ radical-initiated photooxidation of isoprene [46], reactions of monoterpenes with $\mathrm{O}_{3}$ [35], and reactions of $n$-alkanes with $\mathrm{OH}$ radicals [34]. Heterogeneous acid-catalyzed reactions in the particle phase are important mechanisms of SOA formation. Inorganic acids, such as sulfuric acid, catalyze particle-phase heterogeneous reactions of atmospheric organic carbonyl species, which results in a large increase in SOA mass and stabilized organic layers as particles age [47]. Chemical formation and transformation of SOAs by homogeneous reactions are followed by condensation and/or by heterogeneous reactions on particle surfaces and/or in clouds [1]. A number of studies have been performed on the chemical processing of organic compounds in the atmospheric aqueous phase (i.e., rain, clouds, fogs, and aqueous aerosol particles). Aqueous-phase oxidation of isoprene products is considered as an important source of SOAs [2]. The gas/particle partitioning of SOAs is generally described using the theoretical foundations of OA phase partitioning developed by Pankow [26] and extended to SOA formation by Odum [48]. Recently, the "volatility basis-set" (VBS) approach was developed in order to efficiently treat both semi-volatile pri- 
mary emissions and SOA production, and then to treat the chemical evolution (aging) of the aggregate distribution of semi-volatile material [49]. Gas-to-particle conversion of semi-volatile organic compounds includes condensation, absorption, and adsorption, which are driven by temperature, relative humidity [38], and the vapor pressures of oxidation products. Nucleation (homogeneous and heterogeneous) of new particles is recognized as a widespread phenomenon but the exact mechanisms of initiation and growth are not well known [9]. Nucleation tends to be important primarily in very clean environments where it competes effectively with uptake of low volatility particle precursors to previously existing particles.

Based on our keyword analysis, the hottest research topic is emission, followed by chemical composition, yield, kinetics, volatility, and size distribution (Fig. 6). There are large uncertainties associated with both anthropogenic and natural emission inventories on regional and global scales [1]. Better understanding of emission inventories will contribute to efficient regulation of emissions and reduction of SOA concentrations [22]. Due to the complexity of SOA, its precursors, and intermediates, identification of chemical composition remains a challenge in SOA research. Many instruments have been developed, but a perfect field instrument with full completeness, high chemical resolution, and high time/size resolution does not yet exist [9]. Volatility is a hot topic because it influences the extent of gas/particle partitioning and aerosol yield, and chemical processes (oxidation reactions in the gas phase and reactions in the particle phase) can change the volatility of organic compounds [31]. The volatility changes arising from these chemical reactions must be parameterized and included in models in order to gain a quantitative and predictive understanding of SOA formation [10]. In addition, the research on dimethylsulfide (DMS) and its oxidation products methane sulfonic acid (MSA) and sulfate aerosol (SA) becomes increasingly important as anthropogenic $\mathrm{SO}_{2}$ emissions have decreased substantially in Europe and North America. The pathway is either going toward SA or MSA depending on $\mathrm{NO}_{x}$ levels [50].

\section{Most-cited publications}

Yearly variations in the number of citations can be used to trace the impact of publications $[13,20,51]$. Miscounting citations may occur due to the possibilities of simple spelling errors in titles and DOIs in articles, or other similar problems in ISI data [52,53], but the main patterns remain [54]. Table 3 shows the top 10 most frequently cited SOA-related publications through 2011. Four were published in Atmospheric Environment (impact factor, IF, = 3.226 in 2010) and in Science (IF = 31.364 in 2010), one in Atmospheric Chemistry and Physics (IF = 5.309 in 2010), and one in Environmental Science and Technology (IF = 4.825 in 2010). Eight publications included authors from the United States and two from Germany and Greece. The most frequently cited publication was "Atmospheric chemistry of VOCs and $\mathrm{NO}_{x}$ " [45] published in Atmospheric Environment and cited 678 times through 2011. It reviewed the present status of knowledge of the gas-phase reactions of inorganic $\mathrm{O}_{x}, \mathrm{HO}_{x}$, and $\mathrm{NO}_{x}$ species and of selected classes of VOCs (alkanes, alkenes, aromatic hydrocarbons, oxygen-containing VOCs, and nitrogen-containing VOCs) and their degradation products in the troposphere. It pointed out the need to quantify the reaction sequences leading to products which partition to the particle phase and lead to SOA formation. The article life of the top 10 most frequently cited publications is shown in Fig. 7. The publication by Kanakidou et al. in Atmospheric Chemistry and Physics and the article by Robinson et al. in Science have rather vigorous article lives and were cited 128 and 96 times in 2011, indicating researchers' attention to the modeling of OA and the contribution of semi- and intermediate volatility precursors to SOAs. Kanakidou et al. [1] defined critical gaps needed to reduce the uncertainties and summarized the emission estimates of primary carbonaceous particles and SOA precursor gases. Robinson et al. [22] used the VBS approach to reveal the contribution of the oxidation of lowvolatility gas-phase species in diesel emissions to SOA production. On the other hand, the publications by Rogge et al. [55] and Kalberer et al. [31] have been cited less and less during the last five years. Half 
(5) of the most cited publications came from the California Institute of Technology. Georgia Institute of Technology, Max Planck Institute for Chemistry, the University of California, Riverside, and the University of Patras each contributed to two of the most cited publications.

Table 3 Top 10 most frequently cited publications during 1976-2011.

\begin{tabular}{|c|c|c|c|c|}
\hline TC-2011 & Year & $\mathrm{C} / \mathrm{Y}$ & Article/Journal & Country \\
\hline 678 & 2000 & 57 & $\begin{array}{l}\text { Atmospheric chemistry of VOCs and } \mathrm{NO}_{x} / \text { Atmospheric } \\
\text { Environment }\end{array}$ & USA \\
\hline 665 & 2005 & 95 & $\begin{array}{l}\text { Organic aerosol and global climate modelling: } \\
\text { A review/Atmospheric Chemistry and Physics }\end{array}$ & $\begin{array}{l}\text { USA, Greece, Germany, } \\
\text { Italy, Norway, Sweden, } \\
\text { France }\end{array}$ \\
\hline 564 & 1993 & 30 & $\begin{array}{l}\text { Quantification of urban organic aerosols at a molecular- } \\
\text { level—identification, abundance and seasonal-variation/ } \\
\text { Atmospheric Environment Part A-General Topics }\end{array}$ & USA \\
\hline 522 & 1996 & 33 & $\begin{array}{l}\text { Gas/particle partitioning and secondary organic aerosol } \\
\text { yields/Environmental Science \& Technology }\end{array}$ & USA \\
\hline 421 & 2004 & 53 & $\begin{array}{l}\text { Identification of polymers as major components of } \\
\text { atmospheric organic aerosols/Science }\end{array}$ & Switzerland \\
\hline 374 & 2004 & 47 & $\begin{array}{l}\text { Formation of secondary organic aerosols through } \\
\text { photooxidation of isoprene/Science }\end{array}$ & $\begin{array}{l}\text { Belgium, Germany, } \\
\text { Australia, Brazil }\end{array}$ \\
\hline 355 & 1994 & 20 & $\begin{array}{l}\text { An absorption-model of the gas aerosol partitioning } \\
\text { involved in the formation of secondary organic aerosol/ } \\
\text { Atmospheric Environment }\end{array}$ & USA \\
\hline 327 & 2007 & 65 & $\begin{array}{l}\text { Rethinking organic aerosols: Semivolatile emissions and } \\
\text { photochemical aging/Science }\end{array}$ & USA, Greece \\
\hline 326 & 2002 & 33 & $\begin{array}{l}\text { Heterogeneous atmospheric aerosol production by acid- } \\
\text { catalyzed particle-phase reactions/Science }\end{array}$ & USA \\
\hline 311 & 1995 & 18 & $\begin{array}{l}\text { Identification of secondary organic aerosol episodes and } \\
\text { quantitation of primary and secondary organic aerosol } \\
\text { concentrations during SCAQS/Atmospheric Environment }\end{array}$ & USA \\
\hline
\end{tabular}

TC-2011: total citations of articles from publication to 2011; C/Y: number of citations/year. 

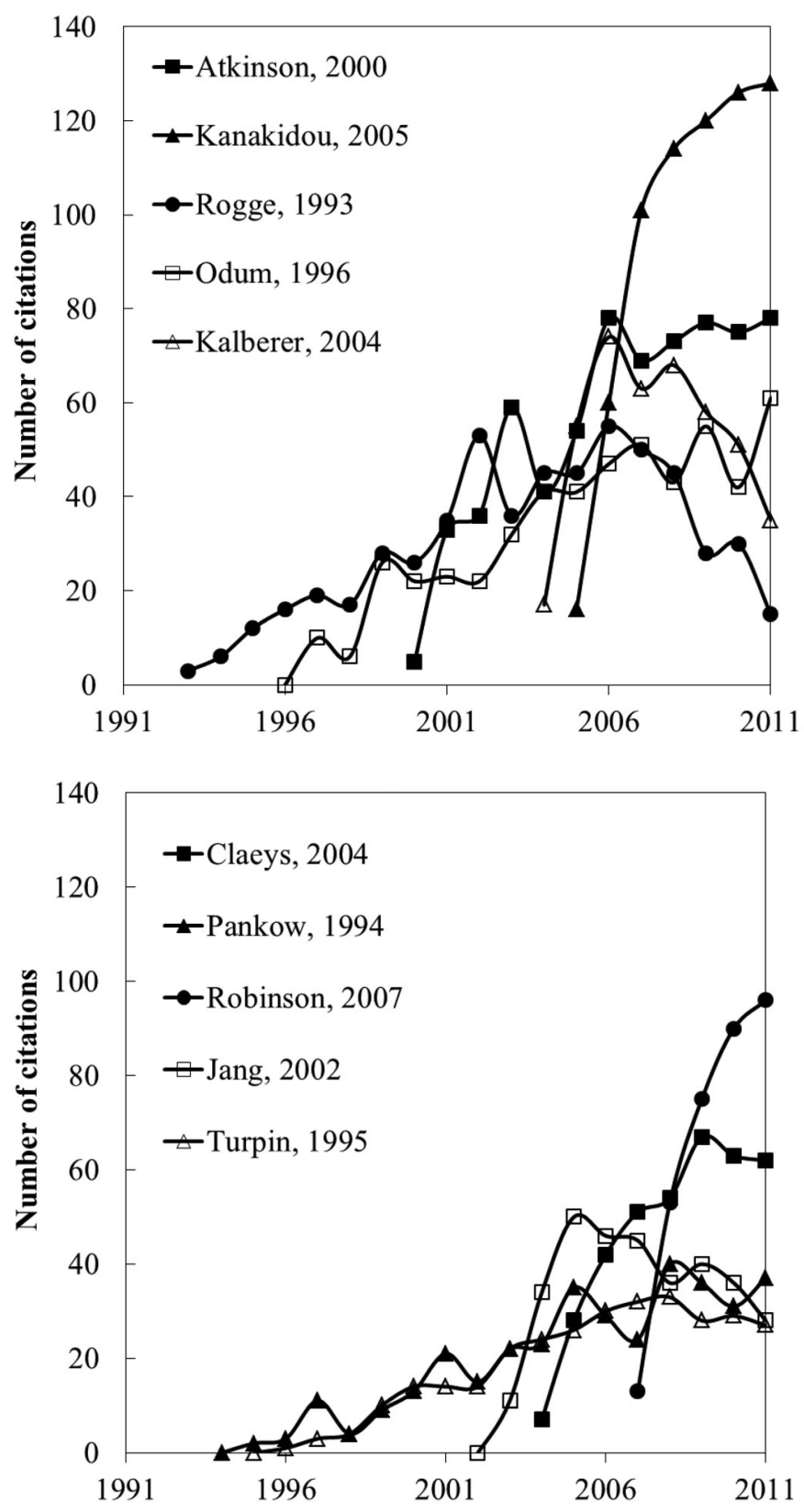

Fig. 7 Citation history of the top 10 most frequently cited articles from Table 3.

\section{CONCLUSION}

In this study on SOA publications listed in SCI-EXPANDED, significant findings on worldwide research performance from 1992 to 2011 were obtained. A total of 148 journals were listed in the 35 SCI subject categories. The greatest number of publications appeared in the journal Atmospheric Chemistry and Physics $(332,19.4 \%)$ and the subject category of meteorology and atmospheric sciences (1004). It is notable that the most times cited per publication appeared in 1992 and 1995 following the 
development of a Lagrangian trajectory model (1992) and an EC tracer method (1995). Analysis of the most-cited publications demonstrate researchers' attention to the modeling of OAs and the contribution of semi- and intermediate volatility precursors to SOA. By synthetically and innovatively analyzing the distribution and changes of author keywords, KeyWords Plus, and words in publication titles and abstracts, the development of SOA research during the last decade is described, and the future orientation of SOA research is predicted. Analysis by a new bibliometric method- "word cluster analysis"can help researchers realize the panorama of global SOA research and establish future research directions. It can be concluded that, at least over the next decade, modeling will continue to be the predominant research method, while the foci of SOA research will be the key SOA precursors terpenes and isoprene, the mechanisms of gas- and condensed-phase oxidation reactions, and emission inventories.

\section{MEMBERSHIP OF SPONSORING BODY}

Membership of the IUPAC Chemistry and the Environment Division Committee for the period 2012-2013 is as follows:

President: L. L. McConnell (USA); Secretary: W. J. G. M. Peijnenburg (Netherlands); Past President: N. Senesi (Italy); Titular Members: E. Cukrowska (South Africa); P. Fedotov (Russia); S. Herve (Finland); G. Jiang (China); N. Kandile (Egypt); W. Kördel (Germany); P. Wine (USA); Associate Members: M. Dassenakis (Greece); H. Garelick (UK); L. Klasinc (Croatia); N. Mañay (Uruguay); K. Racke (USA); B. Xing (USA); National Representatives: M. Carlos (Spain); M. Choudhary (Pakistan); S. Devotta (India); P. Garrigues (France); M. Goodsite (Denmark); S. Hannongbua (Thailan); R. Kookana (Australia); T.-K. Soon (Malaysia); S. Tepavitcharova (Bulgaria); C. von Holst (Belgium).

\section{REFERENCES}

1. M. Kanakidou, J. H. Seinfeld, S. N. Pandis, I. Barnes, F. J. Dentener, M. C. Facchini, R. Van Dingenen, B. Ervens, A. Nenes, C. J. Nielsen, E. Swietlicki, J. P. Putaud, Y. Balkanski, S. Fuzzi, J. Horth, G. K. Moortgat, R. Winterhalter, C. E. L. Myhre, K. Tsigaridis, E. Vignati, E. G. Stephanou, J. Wilson. Atmos. Chem. Phys. 5, 1053 (2005).

2. M. Claeys, W. Wang, A. C. Ion, I. Kourtchev, A. Gelencser, W. Maenhaut. Atmos. Environ. 38, 4093 (2004).

3. J. W. Boylan, M. T. Odman, J. G. Wilkinson, A. G. Russell. J. Air Waste Manage. 56, 12 (2006).

4. H. J. Lim, A. G. Carlton, B. J. Turpin. Environ. Sci. Technol. 39, 4441 (2005).

5. D. Goto, T. Takemura, T. Nakajima. J. Geophys. Res.-Atmos. 113, D07205 (2008).

6. U. Baltensperger, J. Dommen, R. Alfarra, J. Duplissy, K. Gaeggeler, A. Metzger, M. C. Facchini, S. Decesari, E. Finessi, C. Reinnig, M. Schott, J. Warnke, T. Hoffmann, B. Klatzer, H. Puxbaum, M. Geiser, M. Savi, D. Lang, M. Kalberer, T. Geiser. J. Aerosol Med. Pulm. D 21, 145 (2008).

7. J. N. Cape. Environ. Pollut. 155, 391 (2008).

8. N. M. Donahue, A. L. Robinson, S. N. Pandis. Atmos. Environ. 43, 94 (2009).

9. M. Hallquist, J. C. Wenger, U. Baltensperger, Y. Rudich, D. Simpson, M. Claeys, J. Dommen, N. M. Donahue, C. George, A. H. Goldstein, J. F. Hamilton, H. Herrmann, T. Hoffmann, Y. Iinuma, M. Jang, M. E. Jenkin, J. L. Jimenez, A. Kiendler-Scharr, W. Maenhaut, G. McFiggans, T. F. Mentel, A. Monod, A. S. H. Prevot, J. H. Seinfeld, J. D. Surratt, R. Szmigielski, J. Wildt. Atmos. Chem. Phys. 9, 5155 (2009).

10. J. H. Kroll, J. H. Seinfeld. Atmos. Environ. 42, 3593 (2008).

11. S. D. Xie, J. Zhang, Y. S. Ho. Scientometrics 77, 113 (2008).

12. J. Zhang, M. H. Wang, Y. S. Ho. Int. J. Environ. Pollut. 49, 16 (2012).

13. J. F. Li, M. H. Wang, Y. S. Ho. Global Planet Change 77, 13 (2011). 
14. J. F. Li, Y. H. Zhang, X. S. Wang, Y. S. Ho. Croat. Chem. Acta 82, 695 (2009).

15. N. Mao, M. H. Wang, Y. S. Ho. Hum. Ecol. Risk Assess. 16, 801 (2010).

16. G. F. Zhang, S. D. Xie, Y. S. Ho. Scientometrics 83, 477 (2010).

17. S. N. Pandis, R. A. Harley, G. R. Cass, J. H. Seinfeld. Atmos. Environ. a-Gen. 26, 2269 (1992).

18. B. J. Turpin, J. J. Huntzicker. Atmos. Environ. 29, 3527 (1995).

19. Y. S. Ho. Int. J. Environ. Pollut. 1, 1 (2007).

20. W. T. Chiu, Y. S. Ho. Scientometrics 73, 3 (2007).

21. E. Garfield. Curr. Contents 32, 5 (1990).

22. A. L. Robinson, N. M. Donahue, M. K. Shrivastava, E. A. Weitkamp, A. M. Sage, A. P. Grieshop, T. E. Lane, J. R. Pierce, S. N. Pandis. Science 315, 1259 (2007).

23. T. E. Lane, N. M. Donahue, S. N. Pandis. Atmos. Environ. 42, 7439 (2008).

24. J. L. Jimenez, M. R. Canagaratna, N. M. Donahue, A. S. H. Prevot, Q. Zhang, J. H. Kroll, P. F. DeCarlo, J. D. Allan, H. Coe, N. L. Ng, A. C. Aiken, K. S. Docherty, I. M. Ulbrich, A. P. Grieshop, A. L. Robinson, J. Duplissy, J. D. Smith, K. R. Wilson, V. A. Lanz, C. Hueglin, Y. L. Sun, J. Tian, A. Laaksonen, T. Raatikainen, J. Rautiainen, P. Vaattovaara, M. Ehn, M. Kulmala, J. M. Tomlinson, D. R. Collins, M. J. Cubison, E. J. Dunlea, J. A. Huffman, T. B. Onasch, M. R. Alfarra, P. I. Williams, K. Bower, Y. Kondo, J. Schneider, F. Drewnick, S. Borrmann, S. Weimer, K. Demerjian, D. Salcedo, L. Cottrell, R. Griffin, A. Takami, T. Miyoshi, S. Hatakeyama, A. Shimono, J. Y. Sun, Y. M. Zhang, K. Dzepina, J. R. Kimmel, D. Sueper, J. T. Jayne, S. C. Herndon, A. M. Trimborn, L. R. Williams, E. C. Wood, A. M. Middlebrook, C. E. Kolb, U. Baltensperger, D. R. Worsnop. Science 326, 1525 (2009).

25. R. Strader, F. Lurmann, S. N. Pandis. Atmos. Environ. 33, 4849 (1999).

26. J. F. Pankow. Atmos. Environ. 28, 185 (1994).

27. B. Schell, I. J. Ackermann, H. Hass, F. S. Binkowski, A. Ebel. J. Geophys. Res.-Atmos. 106, 28275 (2001).

28. T. M. Gaydos, R. Pinder, B. Koo, K. M. Fahey, G. Yarwood, S. N. Pandis. Atmos. Environ. 41, 2594 (2007).

29. F. S. Binkowski, S. J. Roselle. J. Geophys. Res.-Atmos. 108, (2003).

30. F. Jiang, Q. Liu, X. X. Huang, T. J. Wang, B. L. Zhuang, M. Xie. J. Aerosol Sci. 43, 57 (2012).

31. M. Kalberer, D. Paulsen, M. Sax, M. Steinbacher, J. Dommen, A. S. H. Prevot, R. Fisseha, E. Weingartner, V. Frankevich, R. Zenobi, U. Baltensperger. Science 303, 1659 (2004).

32. T. E. Kleindienst, D. F. Smith, W. Li, E. O. Edney, D. J. Driscoll, R. E. Speer, W. S. Weathers. Atmos. Environ. 33, 3669 (1999).

33. J. R. Odum, T. P. W. Jungkamp, R. J. Griffin, R. C. Flagan, J. H. Seinfeld. Science 276, 96 (1997).

34. Y. B. Lim, P. J. Ziemann. Environ. Sci. Technol. 39, 9229 (2005).

35. K. S. Docherty, W. Wu, Y. B. Lim, P. J. Ziemann. Environ. Sci. Technol. 39, 4049 (2005).

36. T. E. Kleindienst, E. O. Edney, M. Lewandowski, J. H. Offenberg, M. Jaoui. Environ. Sci. Technol. 40, 3807 (2006).

37. M. R. Canagaratna, J. T. Jayne, J. L. Jimenez, J. D. Allan, M. R. Alfarra, Q. Zhang, T. B. Onasch, F. Drewnick, H. Coe, A. Middlebrook, A. Delia, L. R. Williams, A. M. Trimborn, M. J. Northway, P. F. DeCarlo, C. E. Kolb, P. Davidovits, D. R. Worsnop. Mass Spectrom. Rev. 26, 185 (2007).

38. H. J. Lim, B. J. Turpin. Environ. Sci. Technol. 36, 4489 (2002).

39. N. Takegawa, T. Miyakawa, Y. Kondo, J. L. Jimenez, Q. Zhang, D. R. Worsnop, M. Fukuda. J. Geophys. Res.-Atmos. 111, (2006).

40. P. Paatero, U. Tapper. Environmetrics 5, 111 (1994).

41. Y. H. Zhang, X. L. Zhu, S. Slanina, M. Shao, L. M. Zeng, M. Hu, M. Bergin, L. Salmon. Pure Appl. Chem. 76, 1227 (2004).

42. J. J. Schauer, W. F. Rogge, L. M. Hildemann, M. A. Mazurek, G. R. Cass, B. R. T. Simoneit. Atmos. Environ. 30, 3837 (1996). 
43. N. H. Robinson, J. F. Hamilton, J. D. Allan, B. Langford, D. E. Oram, Q. Chen, K. Docherty, D. K. Farmer, J. L. Jimenez, M. W. Ward, C. N. Hewitt, M. H. Barley, M. E. Jenkin, A. R. Rickard, S. T. Martin, G. McFiggans, H. Coe. Atmos. Chem. Phys. 11, 1039 (2011).

44. I. M. Ulbrich, M. R. Canagaratna, Q. Zhang, D. R. Worsnop, J. L. Jimenez. Atmos. Chem. Phys. 9, 2891 (2009).

45. R. Atkinson. Atmos. Environ. 34, 2063 (2000).

46. M. Claeys, B. Graham, G. Vas, W. Wang, R. Vermeylen, V. Pashynska, J. Cafmeyer, P. Guyon, M. O. Andreae, P. Artaxo, W. Maenhaut. Science 303, 1173 (2004).

47. M. S. Jang, N. M. Czoschke, S. Lee, R. M. Kamens. Science 298, 814 (2002).

48. J. R. Odum, T. Hoffmann, F. Bowman, D. Collins, R. C. Flagan, J. H. Seinfeld. Environ. Sci. Technol. 30, 2580 (1996).

49. N. M. Donahue, A. L. Robinson, C. O. Stanier, S. N. Pandis. Environ. Sci. Technol. 40, 2635 (2006).

50. O. Hertel, J. Christensen, O. Hov. Atmos. Environ. 28, 2431 (1994).

51. Z. Li, Y. S. Ho. Scientometrics 75, 97 (2008).

52. D. Adam. Nature 415, 726 (2002).

53. Nature. Nature 415, 101 (2002).

54. F. W. Schwartz, Y. C. Fang, S. Parthasarathy. Hydrogeol. J. 13, 25 (2005).

55. W. F. Rogge, M. A. Mazurek, L. M. Hildemann, G. R. Cass, B. R. T. Simoneit. Atmos. Environ. a-Gen. 27, 1309 (1993).

Republication or reproduction of this report or its storage and/or dissemination by electronic means is permitted without the need for formal IUPAC permission on condition that an acknowledgment, with full reference to the source, along with use of the copyright symbol $\odot$, the name IUPAC, and the year of publication, are prominently visible. Publication of a translation into another language is subject to the additional condition of prior approval from the relevant IUPAC National Adhering Organization. 